\title{
The activist historian
}

The architectural historian Peter Blundell Jones appears as a protagonist in Prue Chiles, Daniela Petrelli, and Simona Spedale's story, in this issue of arq, about the 2012 renovation of the Arts Tower at Sheffield University (pp. 298-311). The tower is home to the School of Architecture where Blundell Jones was professor. Chiles, Petrelli, and Spedale's text is based on interviews with various stakeholders in the project, including the user client, client's representative, and project manager. The university client discussed her efforts to seek acceptable compromises to make the project happen. She saw the historian as a thorn in her side in this process. He sought doggedly to maintain the integrity of the building's parti through the renovation, rejecting pragmatic compromises in order to defend what he believed to be right, using all the means at his disposal. While his efforts may ultimately have been unsuccessful, at least on his own terms, this episode illustrates Blundell Jones's formidable tenacity: expressed here in his insistence on the intellectual integrity of a work of architecture; also known more widely through his vehement reactions against the orthodox modernism of his own architectural training, and his active promotion of 'another history' of modernism rooted in so-called 'organic' and 'humanist' traditions.

Eamonn Canniffe's obituary for Blundell Jones, also published in this issue (pp. 285-288), recalls him as an activist historian. Blundell Jones's highly respected monographs on Hans Scharoun and Hugo Häring rehabilitated those architects' work, which had slipped out of view, restoring them to the canon of modern architecture. His teaching, alongside the books, emphasised ongoing lessons from these figures and demonstrated their relevance for contemporary design, as much as reinforcing their place in architectural history. Likewise, Blundell Jones's work on Erik Gunnar Asplund, Peter Hübner, and Günter Behnisch articulated those architects for a broader professional audience. Accounting for these 'humanist' architects was one aspect of his scholarly formation; another was his enthusiasm for what could be called bottom-up architectures, specifically vernacular structures of the past and the activist architectures of participatory design in the present. He understood these as interconnected, as expressions of social life and vitality, his own activism here in service of that of others.

Peter Blundell Jones served on arq's Editoral Board since the first issue. He remained a regular contributor, a generous reviewer and a champion of the journal, regularly directing authors in our direction. We remain deeply grateful for his input and this issue is dedicated to his memory.

THE EDITORS 
Access

leading

journals in

your subject

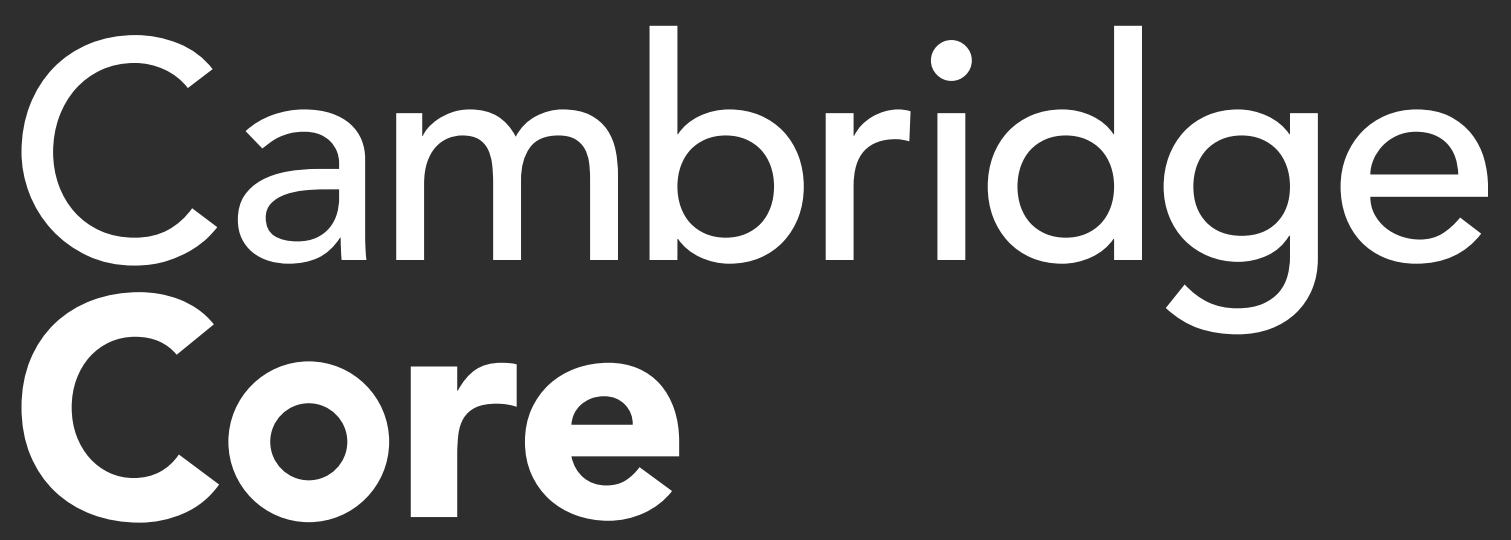

Explore today at cambridge.org/core

Cambridge Core 